\title{
Mercado Pontual: Atuação Estatal na Formação da Feira de Gado de Três Corações (1900-1920)
}

\author{
Alexandre Macchione Saes \\ Professor - Faculdade de Economia, Administração e Contabilidade (FEAVUSP) \\ Endereço para contato: Av. Professor Luciano Gualberto, 908 - Cid. Universitária - SP - Brasil \\ CEP: 05508-010 - E-mail: alexandre.saes@usp.br

\section{Elton Rodrigo Rosa} \\ Graduando em Economia - Universidade Federal de Alfenas (ICSAVUNIFAL/MG) \\ Endereço para contato: Av. Celina Ferreira Ottoni, 4000 - Padre Vitor - Varginha, MG - Brasil \\ CEP: 37048-395 - E-mail: eltonrosa@gmail.com
}

Recebido em 02 de novembro de 2011 . Aceito em 25 de junho de 2013.

\section{Resumo}

O artigo discute a formação da Feira de Gado de Três Corações, analisando os caminhos percorridos pela região na transição da sociedade escravista para a constituição de sua dinâmica capitalista. Para tanto, o texto apresenta uma interpretação para a relação entre Estado e feira de gado mediante o conceito de "mercados pontuais". Considerando que o sul de Minas deve ser analisado como um território marcado por processos históricos particulares, será discutido no texto o porquê de apesar de receber ora influências da economia cafeeira paulista, ora do comércio de abastecimento da cidade do Rio de Janeiro, a região apresentou um crescimento econômico limitado no início do século XX.

\section{Palavras-Chave}

Feira de Gado, Três Corações e capitalismo

\begin{abstract}
The article discusses the formation of the Cattle Market in the city of Três Corações (Minas Gerais/Brazil), analyzing the paths of the region in the transition from slave society to form its capitalist dynamics. To this end, the paper presents an interpretation of the relationship between state and cattle market through the concept of "spot market". Whereas the South of Minas region must be regarded as a territory marked by particular historical processes, is discussed in the text the question why despite receiving either influences the Sao Paulo coffee economy, nor the supplying trade the city of Rio de Janeiro, the region had a limited economic growth in the early twentieth century.
\end{abstract}

\section{Keywords}

Cattle Market, Três Corações - MG, capitalism

\section{JEL Classification}

N56, N46, N76 


\section{Introdução}

Existe um abismo historiográfico entre os aspectos econômicos de Minas Gerais entre os séculos XVIII e XIX e aqueles da transição para o século XX. ${ }^{1}$ Hoje não restam muitas dúvidas sobre o determinante papel desempenhado pela Província de Minas Gerais no abastecimento da Corte e, quiçá, de outras regiões do país, posteriormente a decadência da economia de mineração. ${ }^{2}$ Eram importantes redes mercantis que possibilitavam a disseminação dos mais diversos negócios tanto em Minas Gerais como no Rio de Janeiro desde antes da chegada da Coroa portuguesa até os primeiros anos de Brasil independente. Entretanto, ao nos depararmos com o cenário econômico de Minas Gerais no início do século XX, a Província que outrora demonstrava relativa pujança econômica, passou a ser vista por sua própria elite política como um território economicamente estagnado. Nas palavras do Presidente do Estado João Pinheiro da Silva (1906-1908):

Do exame desta situação, que traduz, tristemente nosso atraso quanto aos problemas econômicos, ao aproveitamento de nossas riquezas naturais, a prática por processos condenados, dos tempos ainda da escravidão, resulta, e com profunda magoa patriótica o dizemos, que, em um Estado de 4.000.000 de habitantes, o algarismo da receita pública se limita a cifra de 16.436:615\$700. Sente-se bem que os sacrifícios para o cumprimento de algum grande dever se estão impondo e que é chegado, srs. representantes de Minas Gerais, o momento de graves reflexões, em que a consciência de um povo se examina nas lições do passado, nas próprias angústias do presente, medindo a ex-

1 Na verdade uma longa literatura se concentra sobre transformações ocorridas no período em Minas Gerais para avaliar o processo de industrialização de Juiz de Fora. Entretanto, poucos são aqueles estudos que exploram as dinâmicas de outras regiões mineiras ou do estado de maneira geral no alvorecer do século XX.

2 Para o papel da Província de Minas Gerais no mercado interno e dos circuitos mercantis no período: MAXWELL, Kenneth. A devassa da devassa. Rio de Janeiro: Paz e Terra, 1979. LENHARO, Alcir. As tropas da moderação. São Paulo: Símbolo, 1979; FRAGOSO, João. Homens de grossa aventura. Rio de Janeiro: Civilização brasileira, 1998; RESTITUTTI, Cristiano Corte. As fronteiras da província: rotas de comércio interprovincial (Minas Gerais, 1839-1884). Araraquara: dissertação de mestrado - UNESP, 2006. 
tensão das faltas cometidas pela grandeza do mal e propondo-se a remediá-lo pela mudança absoluta de rumo. ${ }^{3}$

Não era estagnação econômica, fechada em si mesma, analisada em sua própria, exclusiva e singular dinâmica. Afirmar algo neste sentido seria um completo anacronismo e isolamento do objeto. $\mathrm{O}$ atraso só era diagnosticado na medida em que, por cima de suas montanhas, os mineiros observavam a economia paulista em pleno processo de modernização, enquanto as transformações em sua economia caminhavam ainda muito lentamente. Esse diagnóstico comparativo com São Paulo seria estigmatizado com o conceito de "perda de substância", nas palavras de Francisco Iglesias. ${ }^{4}$ Recuperado nas leituras mais recentes sobre o atraso mineiro no início do século $\mathrm{XX}$, esse atraso relativo de Minas Gerais para o período seria creditado pela perda da "oportunidade histórica" de uma profunda transformação econômica em decorrência da inexistência de um projeto de desenvolvimento, ${ }^{5}$ e da incapacidade do Estado assumir esse empreendimento. ${ }^{6}$

Apesar dessa incapacidade do estado em constituir um projeto de desenvolvimento, vale lembrar que a Primeira República também é conhecida como a "idade de ouro da política mineira". A integração com São Paulo, mediante a política do café-com-leite a partir da reforma do regimento das eleições e o apoio a política de saneamento econômico liderado por Campos Sales, garantia nomeações de políticos mineiros em cargos federais estratégicos e distribuição de recursos para atividades no estado. ${ }^{7}$

3 MINAS GERAIS. Relatórios de Presidente de Província e de Estado, 1907, p. 22-3. Como comparação, a receita ordinária do Estado de São Paulo em 1906 foi orçada em 38.993:213\$827. SÃO PAULO. Relatórios de Presidente de Província e Estado, 1907, p.361.

4 IGLÉSIAS, Francisco. "Política Econômica do Estado de Minas Gerais (1889-1930)". MONTEIRO, Norma (org). Seminário de estudos mineiros: a República Velha em Minas, 5. Belo Horizonte: UFMG, 1982.

5 GODOY, Marcelo Magalhães. "Minas Gerais na república: atraso econômico, estado e planejamento". Cadernos da Escola do Legislativo. Belo Horizonte, vol. 11, n. 16, 2009.

6 DULCI, Otavio. Política e recuperação econômica em Minas Gerais. Belo Horizonte: Ed. UFMG, 1999.

7 MARTINS FILHO, Amilcar Vianna. O segredo de Minas: a origem do estilo mineiro de fazer política (1889-1930). Belo Horizonte: Crisálida, 2009 e WIRTH, John. O fiel da balança: Minas Gerais na federação brasileira (1889-1937). Rio de Janeiro: Paz e Terra, 1982. 
No Sul de Minas Gerais, pode-se notar, essa dinâmica não foi muito diferente. Região com papel decisivo no abastecimento das cidades mineiras no século XVIII e da corte nas primeiras décadas dos oitocentos, o Sul de Minas a partir da segunda metade do século XIX passaria a sofrer algumas importantes transformações. Aproveitandose do crescimento econômico brasileiro de fins de século XIX e dividindo com a Zona da Mata o novo "centro dinâmico" da Província, a região ampliou alguns de seus centros urbanos e, ainda, pode fomentar um pequeno processo de modernização de algumas de suas cidades.

Entretanto, apesar dos relativos avanços, não podemos admitir que a dinâmica de tais transformações tenha seguido o modelo "café-indústria" paulista: ${ }^{8}$ a introdução do café na região em torno de 1880 que, associada à construção de ferrovias, à introdução de empresas de serviços públicos e, inclusive, à formação das primeiras indústrias, apesar de ter dado ao Sul de Minas um maior vigor econômico, não é, nem de longe, um processo similar ao de São Paulo.

Apesar da tendência da economia cafeeira sugar recursos e atrair novos produtores, outras atividades tradicionais mantiveram papel relevante na produção do Estado. ${ }^{9}$ Assim, reafirmando sua função na economia de abastecimento, Minas Gerais era, na passagem do século XIX para o XX, senão o maior, um dos maiores estados ex-

8 Para trabalhos sobre a dinâmica da industrialização baseada no modelo café-indústria paulista: MELLO, João Manuel Cardoso de. O capitalismo tardio. São Paulo: Brasiliense, 1986, SILVA, Sérgio. Expansão cafeeira e origens da industrialização no Brasil. São Paulo: Alfa-Omega, 1976 e CANO, Wilson. Raízes da concentração industrial no Brasil. São Paulo: Difel, 1977. Para aqueles que reproduzem tal leitura para a dinâmica de Minas Gerais, cf: LIMA, João Heraldo. Café e indústria em Minas Gerais, 1870-1920. Petrópolis: Vozes, 1981 e LANNA, Ana Lúcia Duarte. A transformação do trabalho. Campinas: Editora Unicamp, 1989. Questionando a perspectiva em tela, ao tratar da especificidade regional de Juiz de Fora, cf.: PIRES, Anderson. Café, finanças e bancos: uma análise do sistema financeiro da zona da Mata de Minas Gerais (1889-1930). São Paulo: FFLCH/USP, Tese de Doutorado, 2004.

9 É preciso tematizar a referência da expressão "atividades tradicionais". O sentido do adjetivo "tradicional" é aqui duplo. Por um lado, é tradicional no sentido mais imediato do termo, que se refere a algum costume ou atividade arraigada e cristalizada pelo tempo em determinada comunidade. Mas, também, por outro lado, são atividades que não compreendem em si mesmas evoluções e mudanças. São atividades tipicamente pré-capitalistas: se no empreendimento capitalista é necessária uma constante renovação e ampliação do capital, e por consequência aprofundamento da divisão do trabalho e mudanças no modo de produzir, na atividade tradicional, suas estruturas se perpetuam. É interessante notar que embora caso passem a sofrer a coerção do mercado (note-se que no contexto em que analisamos o mercado não aparece como fato coercitivo), historicamente é mais fácil que a atividade tradicional venha a se desintegrar do que se atualizar - no sentido de instaurar relações capitalistas de produção. 
portadores de gado vacum do Brasil. ${ }^{10}$ Essa mercadoria perfazia, em 1903, 19\% das exportações mineiras, atrás apenas do café, que no mesmo ano contribuía com $64 \%$ das mesmas. ${ }^{11}$ Entretanto, no cenário nacional, ao contrário da pecuária em que o Estado demonstrava representatividade, a produção mineira de café era entre cinco e seis vezes menor que a de São Paulo. Se considerarmos que a cafeicultura era a principal direção para a qual se voltavam os olhos dos produtores, tanto frente a incentivos governamentais, quanto por ser a mais rentável das atividades exportadoras do país, pode-se concluir destes dados duas breves conclusões: a primeira delas é a respeito da baixa especialização relativa mineira na produção de café se comparada a São Paulo e, a segunda, é a própria disparidade absoluta em relação ao volume produzido pelas fazendas paulistas. Ou seja, o retardamento da produção cafeeira de Minas Gerais era patente na virada do século, especialmente considerando que, por volta de 1880, as exportações dos dois Estados ainda eram semelhantes. ${ }^{12}$

Assim, o presente artigo discute a formação da Feira de Gado de Três Corações, buscando analisar os caminhos percorridos por uma região na transição de uma sociedade escravista para uma em constituição de sua dinâmica capitalista. Não se tendo, como no contexto de nossa análise histórica, essas condições previamente colocadas (características do mercado capitalista), mas ainda assim se fazendo presentes relações econômicas de circulação de mercadorias com relativa perenidade, acepção deste tipo de mercado deve ser diferente: ele se baseia onde há indícios de um modo de produção capitalista, ${ }^{13}$ mas não é o capitalismo efetivamente constituído. ${ }^{14} \mathrm{O}$ texto apresenta uma interpretação, nesse caso particular, para a relação

${ }^{10}$ O Estado se beneficiava das rotas dos rebanhos, cuja criação era realizada no "Brasil Central", e cruzava Minas Gerais para alcançar os principais mercados consumidores.

${ }^{11}$ COSTA, Fernando Nogueira da. Bancos em Minas Gerais (1889-1964). Campinas: Dissertação de Mestrado - IFCH/Unicamp, 1978, cap. 2.

${ }^{12}$ DINIZ, Clélio Campolina. Estado e capital estrangeiro na industrialização mineira. Belo Horizonte: UFMG/PROED, 1981, p.101.

${ }^{13}$ É interessante notar o papel da circulação de mercadorias para o desenvolvimento da própria produção capitalista. Apenas como ilustração, nas palavras de Lênin: "Sabe-se que a circulação mercantil precede a produção mercantil e constitui uma das condições (não a única) do seu surgimento". LENIN, Vladmir Ilitch. O desenvolvimento do capitalismo na Rússia. São Paulo: Abril Cultural, 1982, p. 347. Cabe lembrar também que, embora no Brasil não houvesse produção em um modo efetivamente capitalista, estava inserido em uma totalidade mundial cujas relações dominantes eram capitalistas.

${ }^{14}$ Para o sentido de capitalismo, cf. DOBB, Maurice. A evolução do capitalismo. São Paulo: Abril Cultural, 1982. Para uma análise detalhada de como as relações econômicas capitalistas tomam forma num mercado capitalista, cf. BRENNER, Robert. "The agrarian roots of European capitalism". ASTON, T.H. \& PHILPIN, C.H. (Ed.). The Brenner debate. Cambridge: Past and Present Society, 1976. 
entre o Estado e a comercialização do gado, ${ }^{15}$ mediante a categoria "mercado pontual", entendido enquanto complexo de circulação mercantil advindo, neste caso, da necessária intervenção do governo na promoção desta atividade econômica - ou mais especificamente, para sua realização final (sua venda). Pontual, porque essa forma de mercado observada não pode ser caracterizada de maneira genérica como simplesmente mercado; essa espécie de mercado, comumente e corriqueiramente referida, é mercado capitalista. O mercado capitalista, para sua formação, pressupõe condições históricas onde se ocorra minimamente a separação do produtor direto com seus meios de produção, de onde surge como consequência o próprio mercado como mediador universal, seja da reprodução social, como da individual.

O Mercado pontual, nesta perspectiva por nós proposta, não possui as condições intrínsecas ao mercado capitalista quanto sua capacidade de eliminar atividades tradicionais. Afinal, é o mercado - em seu sentido pleno - que impulsiona a dinâmica capitalista ao empreender a produtividade não como oportunidade, mas como imperativo ao produtor: ${ }^{16}$ a competição exige a contínua aceleração do desenvolvimento das forças produtivas. A inexistência deste mercado pleno em Minas Gerais poderia ser resultado do fator wakefield, ${ }^{17}$ que inviabiliza a formação de uma classe trabalhadora livre e, consequentemente, um mercado consumidor. O mercado pontual, tentativa do Estado de fortalecer a atividade econômica regional, por ser exogenamente implementado e não ter correspondência nos elementos da formação social regional, não se efetiva. Ainda faltava garantir que os trabalhadores se colocassem como trabalhadores assalariados e que o mercado não fosse muito instável. ${ }^{18}$

${ }^{15} \mathrm{O}$ comércio de animais envolvia atividades com o gado cavalar, muar, vacum, etc. A partir de agora, entretanto, usaremos o termo gado genericamente para identificar a atividade que envolve o comércio do gado vacum especificamente.

${ }_{16}^{16}$ WOOD, Ellen. A origem do capitalismo. Rio de Janeiro: Zahar, 2001, p.84/5.

${ }^{17}$ MARTINS, Roberto Borges. Minas Gerais, século XIX: tráfico e apego à escravidão numa economia não-exportadora. Estudos Econômicos, Instituto de Pesquisas Econômicas - USP, v. 13, n. 1, 1983.

18 Vale recuperar a argumentação de Celso Furtado (1959) ou mesmo de Castro (1969) de que nos momentos de crise a economia brasileira (especialmente como economia escravista) tendia a reversão estrutural, caminhando para a subsistência. Neste sentido, como deixa claro Furtado, não é possível contar com a formação de um mercado consumidor nacional. Cf: FURTADO, Celso. Formação Econômica do Brasil. Companhia Editora Nacional, 1959 e CASTRO, Antonio Barros. "Modelo histórico latino-americano". 7 ensaios sobre a economia brasileira. Rio de Janeiro: Forense, 1969. 
Em suma, o mercado é pontual, como uma instituição, e pode-se considerá-lo assim, ainda mais por sua tendência a não universalização intrínseca a seu próprio funcionamento. E, precisamente, essa sua limitação básica e essencial é sua razão de ser. Limitando-se geograficamente, temporalmente e com relação à diversidade de mercadorias, esse mercado atende a uma produção necessariamente limitada cujas condições de produção são problemáticas; o serviço prestado por esse mercado, frente as suas limitações, permite que se concentrem minimamente produtores e consumidores de uma maneira tal que ele não ocorreria espontaneamente. Com isso, decorrências importantes se sucedem: o produtor tem maior perspectiva de sua venda, tem uma maior condição de certa previsibilidade de custos - ainda que permaneça bastante limitada - tem mais próximo de si o ponto final de sua vendagem. Portanto, é diante dessa diversidade categorial de mercado e da diversidade de condições postas que o Sul de Minas deve ser analisado como um território marcado por processos históricos particulares, pois, apesar de receber ora influências da economia cafeeira paulista, ora do comércio de abastecimento com a cidade do Rio de Janeiro, pode-se dizer que a região teve um crescimento econômico limitado.

Crescimento esse que mais facilmente buscou reconstruir, frente às suas limitações, atividades tradicionais locais possibilitadas pelas feiras de gado, ao invés de planejar e criar meios para, por exemplo, a emergência de uma economia baseada na produção industrial. Por outro lado, e talvez por isso seja difícil estabelecer uma relação de causalidade precisa, a formação do mercado interno depende, além do desenvolvimento do capitalismo em profundidade, ou seja, crescimento da agricultura e indústria capitalistas num mesmo espaço determinado, também é necessária a ampliação da sua esfera para demais territórios. ${ }^{19}$ E este era um movimento que não era, de modo algum, observado na região em alguma escala minimamente representativa.

O presente artigo está dividido em outras cinco partes além desta introdução. Na parte 2 será apresentada uma síntese da evolução do comércio de gado em Minas Gerais no século XIX, introduzindo a ideia de uma velha e outra nova estrutura de comercialização do gado - esta última resultante da introdução das ferrovias na região.

19 Cf. LENIN, 1982, p. 372. 
A parte 3 do artigo avança para o estudo da constituição da Feira de Gado de Três Corações, feira que terá um papel central no mercado de gado na região no início do século XX. A parte 4 mostrará os limites impostos à existência da Feira de Gado de Três Corações, retomando a problemática do mercado pontual e discutindo as deficiências de Minas Gerais para superar sua condição de "perda de substância". Finalmente, serão apresentadas as considerações finais.

\section{O Velho e o Novo Comércio de Gado em Minas Gerais}

O território mineiro ao longo do século XIX foi marcado pela expansão das atividades ligadas ao comércio de abastecimento, em especial àquele direcionado ao consumo da Corte e, posteriormente, à capital do Império, a cidade do Rio de Janeiro. Dentre as atividades da economia mineira oitocentista a pecuária teria papel especial. Entretanto, mesmo tratando-se de uma atividade de destaque na Província, ainda no século XIX, sua estrutura permanecia intocada: o sistema de comercialização e criação pouco havia se transformado daquilo que fora no período colonial. Apesar de importante papel na abertura de fronteiras e integração do mercado interno, o gado continuava criado extensivamente, precisando percorrer longos percursos entre pastos, invernadas e mercados consumidores, construindo uma complexa rede comercial envolvendo negociantes, criadores, invernistas e marchantes. ${ }^{20}$

Até meados do século XIX a comercialização de animais dividiria a pauta de exportações mineiras com ouro e diamantes, para assumir definitivamente a segunda posição a partir de meados da década de 1860, perdendo apenas para o café que entre 1818-1884 perfez $47,1 \%$ do total das exportações. Na média do período, a pecuária representou $25,2 \%$ do total das exportações mineiras, ou cerca de cinquenta

${ }^{20}$ Para textos clássicos sobre a pecuária colonial e sua produção extensiva: ABREU, J. Capistrano de. Capítulos de História Colonial: 1500-1800. Brasília: Conselho Editorial do Senado Federal, 1998; PRADO JR., Caio. História econômica do Brasil. São Paulo: Brasiliense, 1977 e PETRONE, Maria Thereza Schorer. "As áreas de criação de gado". HOLANDA, Sérgio Buarque (org.). História da civilização brasileira. A época colonial. Tomo I, $2^{\circ}$ volume. Rio de Janeiro: Bertrant Brasil, 1993. Para uma descrição contemporânea, cf.: SAINT-HILAIRE, Auguste de. Viagens às nascentes do rio São Francisco. Belo Horizonte/São Paulo: Itatiaia/ Edusp, 1975 e Viagem pelas Províncias do Rio de Janeiro e Minas Gerais. Belo Horizonte/ São Paulo: Itatiaia/Edusp, 1975. 
por cento se excluirmos os valores referentes ao comércio de café, ${ }^{21}$ como é possível visualizar no Gráfico 1.

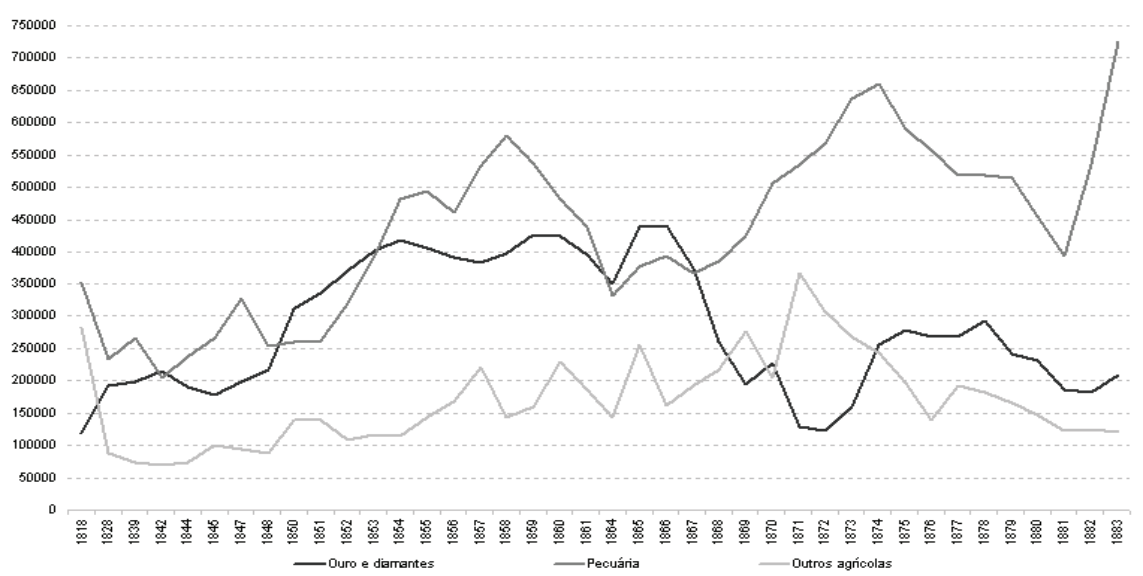

Gráfico 1 - Composição das exportações mineiras exclusive café, 1818-84 (libras esterlinas)

Fonte: Restitutti, 2006, p.80.

Assim, nas primeiras décadas do século XIX, o gado bovino era criado sem maiores recursos nas diversas regiões da Província de Minas Gerais, que eram abastecidas também pelas criações existentes no Brasil Central. Os criadores vendiam seu gado nas feiras livres para os invernistas, estes concentrados na região entre Alfenas e São João del Rei, enquanto a procedência do gado estava espalhada pelo território mineiro e áreas adjacentes: nas bacias do Rio Grande e São Francisco, no oeste e noroeste mineiro, nas regiões do Triangulo Mineiro, e nas Províncias do Mato Grosso, Goiás e oeste paulista. ${ }^{22}$

\footnotetext{
${ }^{21}$ RESTITUTTI, 2006, p.78-82.

${ }^{22} \mathrm{O}$ comércio em expansão no Sul de Minas colocaria em choque os interesses dos comerciantes locais, sitiados, por exemplo, na região de Campanha, com aqueles de São João del Rei, mais bem atendida pelas estradas da Província. Nesse sentido é que se justifica a construção da estrada do Picu, ligação direta entre o Sul de Minas e a Corte. Para o percurso do comércio mineiro no início dos oitocentos, por meio do Caminho Velho, Novo e Estrada do Comércio, da Polícia e, finalmente, do Picu, conferir: GIOVANINI, Rafael. Regiões em movimento: um olhar sobre a Geografia Histórica do Sul de Minas e da Zona da Mata (1808-1897). Belo Horizonte: Dissertação de Mestrado - UFMG, 2006, p.78-84. Para uma descrição do conflito entre as duas regiões e ascensão do Sul de Minas nos quatros políticos da Província, cujo marco dessa ascensão é a Revolução Liberal de 1842, o texto fundamental é ainda o de Alcir Lenharo (1979).
} 
O gado transacionado era conduzido para zonas de invernada e engorda e, mais tarde, seguiria em direção ao Rio de Janeiro, local em que os marchantes se responsabilizavam pelo corte e distribuição da carne pelo mercado. ${ }^{23}$

A cidade de São João del Rei, assim, em parte, recebia o gado das regiões Norte e Sudoeste da Província, fazendo o papel não apenas de uma região de invernadas, como também de um lugar que concentrava as transações mercantis, desempenhando a função de intermediário entre o mercado do Rio de Janeiro e as regiões de abastecimento. ${ }^{24}$ Entretanto, essa estrutura de comercialização de gado que legou às elites são-joanenses papel de articulador comercial e financeiro entre Rio de Janeiro e Minas Gerais até meados do século XIX, vai perder espaço quando marchantes associados ao arrematante e pecuarista sul Mineiro, Francisco José de Mello e Souza, organizam uma companhia para monopolizar o comércio de carne para o Rio de Janeiro. Os relatórios da Câmara Municipal de São João del Rei apontariam uma tendência à queda da atividade no final da década de 1850, quando Mello e Souza teria aberto 30 açougues na capital, redirecionando para o Sul de Minas a organização do comércio de carne da Província. ${ }^{25}$

Articulando-se com o Sul de Minas, o Triângulo Mineiro e a região do Sudoeste de Minas, já em meados do século XIX, foram se tornando regiões ainda mais relevantes na participação dos negócios com o gado. Cidades como Uberaba, Passos e São Sebastião do Paraíso, no início dos oitocentos, não eram propriamente cidades de criação de gado, mas crescentemente concentrariam a chegada do gado da fronteira, tornando-se um ponto importante de invernada. Entre os fatores que permitiram a expansão desse tipo de atividade na região, e que assumiria significativo papel a partir de 1850, estava a excelente fertilidade dos pastos formados com "capim gordura". ${ }^{26}$

${ }^{23}$ Para o comércio de gado em Minas Gerais na transição do século XVIII para o XIX, conferir: PAIVA, Clotilde Andrade. População e economia nas Minas Gerais do século XIX. Tese (Doutorado em História Social) - FFLCH/USP, 1996; CARRARA, Ângelo Alves. Agricultura e pecuária na capitania de Minas Gerais (1674-1807). Tese (Doutorado em História) IFCS/UFRJ, 1997 e CHAVES, Cláudia Maria das Graças. Perfeitos negociantes: mercadores das minas setecentistas. São Paulo: Annablume, 1999.

${ }^{24}$ GRAÇA FILHO, Afonso de Alencastro. A Princesa do Oeste e o Mito da Decadência de Minas Gerais. São João del Rei (1831-1888). São Paulo: Annablume, 2002, p.83.

${ }^{25}$ Ibid. p. 198-9.

${ }^{26}$ NASCIMENTO, Eduardo Rodrigues do. O comércio de gado no sudeste de Minas Gerais: Passos 1830-1900. Ribeirão Preto: Monografia - FEA-RP/USP, 2008; GRILO, Antônio Theodoro. Câmara Municipal de Passos - 150 anos. Passos: Câmara Municipal de Passos, 
O sertão da Farinha Podre (posteriormente arraial de Desemboque - fundado em 1735), como era conhecida a região do Triângulo e do Sul de Goiás no século XVIII, evoluiria então, de decadente extração aurífera e da posterior atividade de abastecimento para se tornar centro de engorda das tropas e, inclusive, de criação de gado. ${ }^{27}$

Assim, em meados do século XIX, as boiadas seguiriam rumo ao Sul da Província, com trilhas pelos rios Verde, Grande e Preto, alcançando então o Rio de Janeiro. O gado que deslocado de Minas Gerais dificilmente seguia para ser comercializado em São Paulo que tinha seu próprio abastecimento. Todavia, o deslocamento para a fronteira paulista também foi opção para que o gado seguisse em direção ao principal mercado consumidor de carne verde do país, a capital do Império, via Vale do Paraíba. ${ }^{28}$ Aproveitando-se das rotas do gado, como descreve o Almanach Sul-Mineiro, as cidades de Caldas e Alfenas também passaram a ser incorporadas como áreas de invernada e de criação na década de $1870 .{ }^{29}$ Tais mudanças sedimentavam a crescente importância exercida pelos representantes do Sul de Minas tanto em sua participação política provincial como responsáveis por atividades econômicas de abastecimento, sedimentando sua independência da Comarca do Rio das Mortes. ${ }^{30}$

Assim, ao longo do século XIX vai se consolidando a posição da fronteira sul como principal caminho das exportações provinciais. Entre 1839 e 1884, tal região respondeu por $29 \%$ das exportações totais da Província, e, se excluirmos o café que assumiria papel decisivo nas rendas de Minas Gerais a partir de 1850, por meio da produção da Zona da Mata, a fronteira sul representaria $67 \%$ do total das

1998.

27 PERINELLI NETO, Humberto. Nos quintais do Brasil: homens, pecuária, complexo cafeeiro e modernidade - Barretos (1854/1931). Franca: Tese de Doutorado - UNESP/Franca, 2009, p.83/4.

28 Renato Marcondes considera que o caminho da Piedade, ligação comercial entre São Paulo e Rio de Janeiro, foi também usado por parte dos rebanhos do Sul de Minas que avançavam para a fazenda Santa Cruz no Rio de Janeiro. MARCONDES, Renato Leite. "Formação da rede regional de abastecimento do Rio de Janeiro: a presença de negociantes de gado (18011811)". Topoi. Rio de Janeiro: 2001, p.10-2.

${ }^{29}$ VEIGA, Bernardo Saturnino da. Almanach Sul-Mineiro para 1874. Campanha: Typ. do Monitor Sul-Mineiro, 1874, p. 35.

${ }^{30}$ A origem do Sul de Minas é a formação da cidade de Campanha em 1789, contudo, ainda como parte da Comarca do Rio das Mortes. Somente em 1833 a Comarca do Rio Sapucaí (posteriormente Sul de Minas) teria sua autonomia definida, delimitada pela Mantiqueira nas fronteiras de São Paulo e Rio de Janeiro e o Rio Grande ao Norte, cf.: ANDRADE, 2008, "Introdução". Afonso Alencastro argumenta que o Sul de Minas manteve subordinado ao centro financeiro regional estabelecido na cidade de São João Del Rei, mas como defende Alcir Lenharo, a Revolta Liberal de 1842, por sua vez, marcou a definitiva afirmação dos grupos sul-mineiros na política da Província. Cf.: GRAÇA FILHO, 2002; LENHARO, 1979, p.137. 
exportações. Destas restantes, $70 \%$ eram originárias das atividades relacionadas à pecuária. O Sul de Minas concentrava, desta forma, as típicas atividades ligadas ao comércio de abastecimento, concentrando o trânsito provincial do fumo (91\%), de suínos (90\%), de bovinos (80\%), de queijos (67\%) e de toucinho, banha e carne de porco $(54 \%)$.

A partir de fins do século XIX, o gado que partia da região do Triângulo Mineiro, depois da engorda nas invernadas Uberaba, ou cruzando pela invernada de Passos, passou a percorrer dois trajetos para atender seus mercados consumidores: ou era levado para Três Corações do Rio Verde, comercializado posteriormente para o mercado do Rio de Janeiro, ou então corria em direção à cidade de Barretos, atendendo daquela cidade o mercado paulista. ${ }^{32}$ Conforme relata Antônio Celestino sobre Passos:

Toda a pujança do município brotava das patas de bois invernados... Mas, não só. Esse tipo de pecuária estava profundamente atrelado ao comércio. O ciclo 'produtivo' começava pela compra de gado nos sertões e só se completava com a exportação das boiadas aos abatedouros da Corte, através do 'marchand' e dos 'comércios' de embarque, em Três Corações do Rio Verde. ${ }^{33}$

Mas a transição para o século XX marcou um período em que o comércio de gado sofreria profundas transformações. Era, o que podemos chamar, da passagem da velha estrutura de comercialização para a nova, que seria influenciada pelas novas rotas de comércio, pelo transporte ferroviário e pela gradual substituição dos agentes vinculados a essa atividade. Em Passos essa mudança aparece com o abandono das velhas práticas de invernada, que nas palavras de Antônio Grilo teria feito a riqueza do município nas décadas anteriores, para o aparecimento da criação de gado de raça, com a introdução do zebu, e a pecuária leiteira. ${ }^{34}$

\footnotetext{
31 RESTITUTTI, 2006, cap. 8 e 9.

${ }^{32}$ NORONHA, Washington Álvaro de. História da cidade do Senhor Bom Jesus dos Passos. Edição Oficial Municipal, 1969.

33 Antonio Celestino, "Os contratadores da Morte", Apud, NASCIMENTO, 2008, p.23.

${ }^{34}$ GRILO, Antônio Theodoro. Câmara Municipal de Passos - 150 anos. Passos: Câmara Municipal de Passos, 1998, Apud, NASCIMENTO, 2008, p. 36.
} 
E, para o Sul de Minas, a cidade de Três Corações do Rio Verde surgia no mapa da comercialização do gado mineiro com a inauguração da Estrada de Ferro Minas e Rio na cidade em 1884. A partir desse investimento inicial, outras ferrovias seriam criadas na região, de maneira que, entre 1890 e 1906, a malha ferroviária do Sul de Minas passaria de $246 \mathrm{Km}$ para $923 \mathrm{Km}$, enquanto aquela referente à Zona da Mata, local onde se concentravam os principais investimentos de Minas no período, em decorrência da produção cafeeira, cresceria apenas $86 \mathrm{Km}^{35}$ Em suma, as estradas de ferro redefiniriam os trajetos pelo qual o gado seguiria seu caminho para o mercado consumidor: as pastagens e invernadas tradicionais dos caminhos para o Rio de Janeiro perdiam espaço para novas localidades próximas às estações ferroviárias. É nesse contexto que, aproveitando-se de condições favoráveis, o governo de Minas Gerais reafirmaria a prática do abastecimento como atividade central de sua economia, criando por intermédio da ação do estado, o chamado mercado pontual, isso é, a Feira de Gado de Três Corações.

\section{A Feira de Gado de Três Corações}

O município de Passos pode ser considerado o ponto de partida de onde nasceria a Feira de Gado de Três Corações. Desde a metade do século XIX, o município já possuía negócios de abastecimento de gado em articulação com o Rio de Janeiro, principalmente, sendo "um daqueles que exportam em grande quantidade para o consumo desta Corte". ${ }^{36} \mathrm{E}$, como membros respeitáveis no negócio, ainda que neste período - entre 1860 e 1868 - "o gado tenha arruinado ali algumas fortunas", constavam os irmãos Abreu. ${ }^{37}$

${ }^{35}$ GIOVANINI, 2006, p. 188. Para as ferrovias em Minas: BLASENHEIN, Peter Louis. $A$ regional history of the Zona da Mata in Minas Gerais, Brazil: 1870-1906. Stanford: Tese Stanford University, 1982.

${ }^{36}$ BRETAS. Discurso proferido a 26 de julho de 1862. Annaes do Parlamento Brazileiro: sessão de 1862. Tomo III. Rio de Janeiro: Typographia Imperial e Constitucional de J. Villeneuve \& C., 1862, p. 243.

${ }^{37} \mathrm{Na}$ década de 1820 as famílias de Manoel José Lemos e de seu cunhado João Pimenta de Abreu se instalariam no território da futura cidade de Passos, com propriedades beirando o Rio Grande. João Pimenta de Abreu, pai dos "irmãos Abreu", seria um dos responsáveis para formação da paróquia de Passos em 1840, e mais tarde, sua família estaria amplamente envolvida com os negócios de gado. NASCIMENTO, 2008, p.16. 
Foi com a chegada da Estrada de Ferro Minas and Rio até Três Corações em 1884 - ferrovia cujo entroncamento na cidade de Cruzeiro era feito com a E.F. D. Pedro II, no vale do Paraíba paulista -, que parte dos negócios de gado se deslocaria definitivamente de Passos. A estrada de ferro chegaria por falta de recursos, de fato, somente até Três Corações - e não como se previa anteriormente, até Barra do Pontal - ponto navegável no Rio Verde, que poderia articular uma mais ampla estrutura de transportes -, ocasionando diversas reclamações segundo negociantes em Passos. ${ }^{38}$ Vale lembrar que para o abastecimento de carne verde ao Sul de Minas - criação ou pastagem -, os principais centros de engorda eram além de Passos, a cidade de Uberaba e a de Santa Rita de Cássia: estas últimas, também importavam gado do sertão mineiro e de algumas regiões do centro-oeste. Não chegando a infraestrutura de transporte esperada até aquela região, foi necessário o deslocamento do pólo da atividade: de Passos, um dos irmãos Abreu, Belchior Pimenta, se mudaria para Três Corações.

Tendo ele, então, a partir de seus objetivos conseguido o empreendimento de emancipar em setembro de 1884 o arraial de Três Corações, até aquela data pertencente ao município de Campanha, passando a governá-lo como um dos intendentes da Câmara. Ademais, tornou-se o responsável pelo privilégio de embarcar gado pela ferrovia (junto ao concessionário da Estrada de Ferro Minas e Rio), conquistando também em 1887 os direitos de estruturar a Feira (por meio do aluguel e preparação de terrenos para invernagem e exposição), e nela cobrar impostos. ${ }^{39}$ Embora tenha sido apenas regulamentado pelo estado em 1898, a comercialização do gado na cidade já adquiria uma função de destaque na década anterior. Por meio da Tabela 1 é possível observar a evolução do escoamento de animais pela E.F. Minas and Rio. ${ }^{40}$

\footnotetext{
${ }^{38}$ GIOVANINI, 2006, p. 186.

${ }^{39}$ FONSECA, João Garcia da. Três Corações e sua história. Belo Horizonte: Imprensa Oficial, 1984; SOUSA, Benefredo de. Boiada vai, máquina vem... Pouso Alegre: Tipografia Escola Profissional, 1975.

${ }^{40}$ Os animais referidos são gado vacum, porcos e lanígero. Com exceção dos três primeiros anos, nos demais, o volume de gado vacum perfaz, em média, cifra em torno de $90 \%$ do total.
} 
Tabela 1- Movimento de saída de animais pela E.F. Minas \& Rio

\begin{tabular}{|c|c|c|c|c|c|}
\hline Ano & Animais & Ano & Animais & Ano & Animais \\
\hline 1884 & 2.180 & 1892 & 88.678 & 1900 & 81.645 \\
\hline 1885 & 5.888 & 1893 & 71.298 & 1901 & 79.808 \\
\hline 1886 & 21.469 & 1894 & 79.124 & 1903 & 85.252 \\
\hline 1887 & 61.252 & 1895 & 61.781 & 1904 & 79.911 \\
\hline 1888 & 89.020 & 1896 & 54.643 & 1905 & 108.688 \\
\hline 1889 & 81.917 & 1897 & 82.732 & 1907 & 118.542 \\
\hline 1890 & 89.719 & 1898 & 71.997 & 1908 & 117.626 \\
\hline 1891 & 91.773 & 1899 & 52.501 & & \\
\hline
\end{tabular}

Fonte: Relatórios do Ministério da Agricultura (até 1905); Relatórios do Ministério de Indústria, Viação e Obras Públicas (1907 e 1908). Não consta para os anos de 1902, 1906, 1909 e seguintes.

Nota-se que a partir de 1888 , quando se estabilizou a situação do transporte de animais pela ferrovia, houve um relativo impulso nas exportações dos animais. O governo comemorava o avanço do transporte do gado pela ferrovia, como resultado da "inteligente propaganda" e das concessões feitas pela companhia ferroviária para reduzir o custo do transporte de gado. ${ }^{41}$

No município de Três Corações, por volta do mesmo período, a Companhia Pastoril Mineira já possuía fazendas de pastagem e criação. Esta Companhia, segundo os Relatórios do Ministério da Agricultura dos anos de 1889 e 1890, teria recebido do Estado o direito à subvenção anual de 150:000\$000 por dez anos, que passaria a valer após a instalação de um dos dois matadouros, previstos com a introdução de câmaras de congelamento, e estabelecendo depósitos refrigeradores junto aos mercados consumidores em São Paulo e Rio de Janeiro. Não há menor dúvida, as autoridades buscavam viabilizar a reorganização do setor, lutando para dar conta da modernização do comércio de gado. No entanto, as instalações jamais saíram do papel, com a liquidação da empresa em 1900. ${ }^{42}$

De qualquer forma, a Feira de Gado de Três Corações, no Sul de Minas Gerais, passou a ser regulamentada pelo Estado - além das de Benfica e Sítio (Zona da Mata) -, a partir de 1898. Segundo o Relatório de Presidente do Estado de 1916, teriam sido constituídas "com o intuito de amparar a causa do invernista, até então [1898]

\footnotetext{
${ }^{41}$ MINAS GERAIS. Relatórios de Presidente de Província e Estado, 1887, p. 297.

42 BRASIL. Relatórios do Ministério da Agricultura. (1884 - 1906), 1900.
} 
obrigado a levar o seu gado ao matadouro de Santa Cruz, onde recebia o preço e a senha". Era uma tentativa de fortalecer a atividade no estado, frente ao controle da fase final do comércio concentrado pelos negociantes cariocas. O matadouro Santa Cruz, no Rio de Janeiro, que já se tornara o principal centro de abastecimento de carne verde ao mercado carioca, possuía monopólio concedido pelo governo Floriano Peixoto desde 1891. De acordo com John Wirth, fora concedido "para apaziguar os consumidores de classes médias e baixa, os mais atingidos pela inflação", ${ }^{43}$ e para importar o gado platino, com o objetivo de diminuir os preços domésticos, contra os quais os pecuaristas nacionais deveriam competir.

No momento em que o Estado regulamentava a Feira em 1898, abria-se espaço para que Belchior Pimenta de Abreu e seu afilhado Cristiano José Lemos, levassem a cabo a montagem do negócio de gado na região. Eles conseguiram a concessão junto ao Estado de acordo com as certidões para registros de firmas comerciais, a 20 de novembro de 1900; ${ }^{44}$ constituíram as firmas "Belchior Pimenta à Companhia", sob a categoria de "exploração de contrato da feira de gado"; e a "Cristiano Lemos à Companhia", em 1901, sob a categoria de "companhia, venda e comissão de gado". Regulamentada a Feira, passariam nela a ser cobrados impostos. Este fato motivaria uma maior preocupação quanto à fiscalização do comércio bovino no Estado, já que os condutores tentariam burlá-la: como aconteceria, por exemplo, em 1903, com o embarque parcial do gado direto em Taubaté para o Rio de Janeiro. ${ }^{45}$ A Tabela 2 apresenta os números da Feira de Três Corações:

Tabela 2 - Volume de negócios - Feira Três Corações (gado vacum)

\begin{tabular}{|c|r|c|r|r|r|}
\hline Ano & Cabeças & Ano & Cabeças & Ano & \multicolumn{1}{c|}{ Cabeças } \\
\hline 1902 & 75.503 & 1909 & 101.589 & 1915 & 127.041 \\
\hline 1903 & 78.873 & 1910 & 116.030 & 1916 & 156.332 \\
\hline 1904 & $86.056^{*}$ & 1911 & 125.206 & 1917 & 126.937 \\
\hline 1905 & $99.963^{*}$ & 1912 & 137.188 & 1918 & 116.186 \\
\hline 1906 & $99.681^{*}$ & 1913 & 136.325 & 1919 & $93.928^{*}$ \\
\hline 1908 & 102.885 & 1914 & 132.997 & 1922 & 81.867 \\
\hline
\end{tabular}

Fonte: Relatórios de Presidente de Província e Estado. ${ }^{46}$

43 WIRTH, 1982, p.91.

44 "Caixa de documentos diversos (1899 a 1928)". Cartório de Registro de Títulos e Protestos de Três Corações, $\mathrm{Cx} . \mathrm{n}^{\circ} 1$, contendo: registros de empresas, casas comerciais, pousadas e certidões de registros para firmas comerciais atuantes no município.

45 BRASIL. Relatórios do Ministério da Agricultura. (1884 - 1906), 1904, p. 364.

${ }^{46}$ Nos anos de 1920 e 1921, em função das epidemias na região, não houve Feira. 
O negócio, como se pode ver, embora tenha dado relativos resultados, vinha de uma base produtiva irregular. As oscilações eram constantes, provocadas pela própria estrutura do negócio. Algumas regiões, segundo os Relatórios do Ministério da Agricultura, em determinados períodos, eram vítimas de epidemias. ${ }^{47}$ Tais fatos causavam profunda preocupação para comerciantes e autoridades do Estado, e foram, inclusive, responsáveis pela não realização das feiras de 1920 e 1921. Não obstante, por meio dos Relatórios de Presidente de Província é perceptível a crescente intenção do governo em melhorar as condições de criação e comercialização do gado, com introdução de vacinas, a criação de cursos de veterinária e agronomia, além da introdução de raças importadas. ${ }^{48}$

Independentemente das epidemias, ao longo dos primeiros anos do século XX as condições para o desenvolvimento da comercialização do gado em Três Corações pareciam bastante favoráveis. Em primeiro lugar, o monopólio do matadouro Santa Cruz seria cassado na passagem de século. Ao mesmo tempo, o cenário de valorização da moeda brasileira elevaria o preço do gado platino que, aliado às taxas de importação implantadas no período, protegeriam o produtor nacional. ${ }^{49}$ Finalmente, a melhora das ligações ferroviárias com o Distrito Federal também possibilitava romper, em parte, com as estruturas comerciais dos grupos cariocas. Independentemente desse contexto mais favorável para o setor em Minas, o fato é que o negócio, ainda assim, não progredia.

Já enumerados vários problemas, o principal permanecia a falta de infraestrutura. O peso da mercadoria foi, durante boa parte do funcionamento da feira, avaliado por apreciação visual. A ausência de matadouros e câmaras de resfriamento também condicionou uma relação de dependência com os mercados paulista e carioca. Não bastassem já serem eles os principais mercados consumidores, a con-

Os anos com * correspondem a estimativas baseadas no total negociado em todas as Feiras, retirando-se o percentual médio das negociações em Três Corações. Os demais anos não constam.

47 Na descrição do capitão do exército, Henrique Silva, para as Séries Estatísticas Retrospectivas de 1908: "Nessa zona em que se realizam as vendas, estrada afora, são comum as pestes. Sabemos de boiadeiro que, em 1904, após um percurso de 200 léguas, conduzindo 700 bois, via a peste, no sul de Minas, arrebater-lhe em poucos dias 346 rezes. Sabemos de outro que perdeu toda a boiada. O comércio de gado é, pois, nesta zona, reputado mais um jogo, que um fator econômico social". IBGE. Séries Estatísticas Retrospectivas. Volume 2, Tomo 2. Rio de Janeiro: IBGE, 1986, p. 427.

${ }^{48}$ MINAS GERAIS. Relatórios de Presidente de Província e de Estado (1902-1923).

${ }^{49}$ WIRTH, 1982, cap.2. 
servação do gado abatido dependia de seus frigoríficos. A produção, considerando-se o valor agregado, tornava-se menor do que sua potencialidade permitiria: os outros Estados explorariam a parte "final" da produção, ao agregarem neste estágio maior valor.

Os mercados consumidores locais eram também limitados. Segundo o relatório do Presidente do Estado de 1907, existia uma angústia com a ampliação da produção nacional e sua iminente superprodução, em contraposição ao limitado mercado mineiro. Atingir o mercado internacional e, para isso, modernizar o processo de comercialização do gado era recorrente nos discursos das autoridades:

A solução do problema pecuário em Minas não depende somente das medidas apontadas para desenvolver e melhorar os rebanhos; convém também cogitar da colocação dos produtos nos mercados consumidores. Até aqui a próspera indústria da engorda do gado tem vivido dos mercados internos; hoje, porém, a produção cresceu e já não bastam esses mercados. A situação dos mercados da carne no mundo e o desenvolvimento da pecuária em Minas tornaram urgentes a exportação da carne e a instalação de matadouros frigoríficos. Há muitos anos vem a administração mineira cogitando de dotar o Estado desses matadouros. ${ }^{50}$

A preocupação com a ampliação dos mercados, portanto, também se fazia sentir. E era sempre pautada na mesma questão para sua realização: a de infraestrutura. Entretanto, ainda assim, sem conquistá-la de maneira efetiva, o Estado conseguiu ampliar suas exportações, incluindo-se, inclusive, o acesso aos mercados estrangeiros nos anos 1915 e 1916, mantendo-se em elevados níveis entre 1917 e 1918. De acordo com o relatório do Presidente do Estado de 1916, essa expansão fora causada pelo crescimento da economia nacional no período da $1^{\text {a }}$ Guerra Mundial. O café, por seu turno, com as crises de superprodução, vinha perdendo participação nas rendas de exportação do Estado. Embora o volume de exportação tivesse em contínuo crescimento, relativamente sua participação nas exporta-

\footnotetext{
${ }^{50}$ Mensagem do Presidente de Estado de Minas Gerais Delfim Moreira da Costa Ribeiro. MINAS GERAIS. Relatórios de Presidente de Província e de Estado, 1915, p. 116-7.
} 
ções tinha sido reduzida de cerca de $70 \%$ na última década do oitocentos, para 30\% no período da Grande Guerra. ${ }^{51}$ É possível supor o redirecionamento dos investimentos de parte desses produtores agrícolas antes voltados ao setor exportador para o mercado interno e abastecimento da economia nacional. Por isso mesmo, o gado se aproveitava das melhores condições de comercialização para representar aproximadamente $40 \%$ das exportações mineiras entre 1908 e 1919, quando iniciar-se-ia nova tendência de retração do negócio ao longo da década de $1920 .^{52}$

Assim, apesar de um momento favorável para o comércio de gado no Sul de Minas durante o período bélico, a Feira de Gado de Três Corações sofreria um violento impacto com a modernização da pecuária em São Paulo na década seguinte. Não por acaso, John Wirth indicou que o comércio das regióes do oeste de Minas, Triângulo e Centro-Oeste, ao longo da década de 1910, seriam direcionados para os "compradores paulistas liderados pela Anglo Frigorífico Co., de propriedade britânica" que havia chegado à Barretos em 1913. ${ }^{53}$ Como os matadouros da Pastoril Mineira, ou de qualquer outra empresa mineira, não tinham entrado em operação, a produção frigorífica de Barretos que começara a funcionar na década de 1910 tomaria para si boa parte dos negócios de comercialização do gado de Minas Gerais. Especialmente porque a expansão das criações na região do triângulo mineiro estaria diretamente ligada com o mercado paulista por meio da Estrada de Ferro Mogiana desde 1909. Em suma, no auge da atividade da Feira de Gado de Três Corações, o gado que confluía na direção do Sul de Minas, para ser posteriormente comercializado nos centros urbanos, seria direcionado para outras cidades.

\section{Auge e Crise da Feira de Gado}

O modelo da Feira de Gado de Três Corações, apesar de seu êxito ao longo das duas primeiras décadas do século XX, estava preso ainda aos arcaicos modos de comercialização do gado.

\footnotetext{
${ }^{51}$ VISCARDI, Cláudia. M. R. "Minas Gerais no Convênio de Taubaté: Uma Abordagem Diferenciada". III Congresso Brasileiro de História Econômica e IV Conferência Internacional de História de Empresas, Anais da ABPHE. Curitiba: UFPR, 1999, p.2.

52 WIRTH, 1982, p. 83.

${ }^{53}$ WIRTH, 1982, p. 91. Como veremos a frente, a empresa somente passará para mãos britânicas em 1924.
} 
Enquanto a cidade se tornava o maior centro de distribuição do gado da América Latina, segundo relatos locais, ${ }^{54}$ a produção argentina avançava rapidamente para a modernização de seus negócios. ${ }^{55}$ Intimamente conectada com o mercado inglês, a produção platina já em 1877 teria suas primeiras experiências com a exportação de carne bovina por meio de navios frigoríficos. Talvez, por isso mesmo foi a região fronteiriça com a Argentina e o Rio Grande do Sul, onde a modernização da pecuária no país ocorreria antes: a primeira fábrica de carnes enlatadas no Brasil foi estabelecida perto de Porto Alegre, mediante capital inglês, em 1889; e, poucos anos mais tarde, em 1903, o governador do Rio Grande do Sul, Bordes de Medeiros, buscaria incentivar a instalação de frigoríficos em seu estado, mas sem que o projeto tivesse efetivação imediata. ${ }^{56}$

Ainda na primeira década do século XX, enquanto a produção de café alcançava a recorrente superprodução, outras medidas seriam tomadas pelo governo federal no intuito de estimular a modernização da pecuária nacional. Os incentivos não eram apenas restritos aos interesses nacionais: entre 1905 e 1906, o próprio Cônsul norte-americano no Brasil indicaria o grande potencial para a instalação de frigoríficos no Brasil, dando especial destaque para os estados de Minas Gerais e São Paulo. Apontava o crescente mercado interno como principal elemento impulsionador para a expansão e o melhoramento da produção. Assim, "o próprio governo brasileiro estimulou a indústria. Um decreto de abril de 1910 abria concorrência para a construção de um sistema de entrepostos frigoríficos e matadouros-modelo em diversos estados". ${ }^{57}$

No decreto de 1910 era determinado o livre-imposto para aquisição de máquinas importadas para a constituição dos frigoríficos, subsídios para operações de processamento, armazenamento e transporte do gado. Apesar dos incentivos e das perspectivas positivas de desenvolvimento do setor, poucas propostas foram concretamente elaboradas antes do período da Primeira Guerra Mundial. Todavia, em meados da década de 1910 e, especialmente como resposta ao fortalecimento da pecuária na economia brasileira durante o período armamentista, enfim, a expansão do número de frigoríficos no Brasil aconteceria.

\footnotetext{
${ }^{54}$ FONSECA, João Garcia da. Três Corações e sua história. Belo Horizonte: Imprensa Oficial de Minas Gerais, 1984.

${ }^{55}$ SUZIGAN, Wilson. Indústria brasileira. São Paulo: Hucitec, 2000, p.349.

${ }^{56}$ SUZIGAN, 2000, p.350.

${ }^{57}$ Ibid., p.351.
} 
Tabela 3 - Frigoríficos estabelecidos no Brasil antes da década de 1930

\begin{tabular}{|l|c|c|c|c|c|}
\hline \multicolumn{1}{|c|}{ Companhia } & Localização & Fundação & Operação & Nacionalidade & Capacidade* $^{*}$ \\
\hline Cia. Frigorífica e Pastoril & Barretos, SP & 1910 & 1913 & Brasileira & 4.000 \\
\hline The Continental Products Co. & Osasco, SP & 1913 & 1915 & Americana & 1.000 \\
\hline The Anglo-Brazilian Meat Co. & Santa Cruz, RJ & 1912 & 1917 & Britânica & - \\
\hline Brazilian Meat Co. & Mendes, RJ & - & 1917 & Britânica & - \\
\hline Cia. Armour do Brasil & Livramento, RS & - & 1917 & Americana & 1.000 \\
\hline Cia. Swift do Brasil & Rio Grande, RS & - & 1919 & Americana & - \\
\hline Cia. Frigorífica de Pelotas & Pelotas, RS & 1917 & 1919 & Brasileira & 500 \\
\hline Cia. Frigorífica de Santos & Santos, SP & 1917 & 1918 & Brasileira & - \\
\hline Cia. Amour do Brasil & São Paulo, SP & 1917 & 1921 & Americana & 3.000 \\
\hline Cia. Pecuária e Frigorífica do Brasil & Barbacena, MG & 1916 & 1918 & Brasileira & - \\
\hline Frigorífico Matarazzo & Jaguarialva, PR & 1920 & 1923 & Brasileira & 300 \\
\hline Frigorífico Bianco & Cruzeiro, SP & 1929 & - & Brasileira & 180 \\
\hline
\end{tabular}

* Capacidade de produção (número de cabeças de gado por dia)

Fonte: Suzigan, 2000, p.356.

Vale ressaltar que a função preponderante desses frigoríficos era atender a demanda do mercado interno, embora houvesse exportação em algumas ocasiões. Diferentemente da produção argentina que estava intimamente ligada ao mercado internacional, com destaque ao mercado britânico, as empresas que foram criadas no país deveriam suprir a população urbana que crescia nos estados de São Paulo e Rio de Janeiro. Não é para menos que entre as 12 empresas constituídas antes de 1930, cinco delas estavam no estado de São Paulo, duas no Rio de Janeiro e ainda 1 no Paraná, de propriedade do empresário italiano atuante no mercado paulista, Francisco Matarazzo. E, talvez por atenderem ainda ao mercado local e terem sido formadas no período de guerra, metade dessas empresas eram nacionais. Outras quatro empresas eram norte-americanas e, finalmente, as duas restantes britânicas.

Possivelmente é neste momento que a posição central de Minas Gerais no comércio e na distribuição de gado para os maiores mercados brasileiros se desfaz. Dentre os frigoríficos constituídos no período, Minas Gerais apenas formaria a Cia. Pecuária e Frigorífica do Brasil, instalada nas bordas da Zona da Mata, na cidade de Barbacena. 
A estrutura de comércio de carne verde tendia a ser substituída por carnes refrigeradas e, a circulação do gado passaria paulatinamente a correr para alcançar não mais as feiras de gado mineiras, mas os frigoríficos paulistas e cariocas.

Esse é o caso típico da Companhia Frigorífica e Pastoril de Barretos. A empresa era formada por Antonio da Silva Prado e Alexandre Siciliano: o primeiro era importante membro do grande capital cafeeiro paulista - diretor da Companhia Paulista de Estrada de Ferro -, enquanto o segundo era diretor de um pioneiro frigorífico na cidade de Barretos (da Companhia Mecânica e Importadora de São Paulo). A empresa comprava gado de Mato Grosso, Minas Gerais e São Paulo para engorda nos pastos de Barretos e, posteriormente, a carne era levada para São Paulo e Santos, pelas câmaras frigoríficas da Cia. Paulista. A Pastoril de Barretos, juntamente com a Santa Cruz e a Mendes, ambas britânicas instaladas no Rio de Janeiro, eram as únicas três empresas que realizam exportações. ${ }^{58}$

Essas transformações tecnológicas, não acompanhadas pela pecuária em Minas Gerais, decretariam a crise na Feira de Gado de Três Corações. Entre as causas da crise da pecuária na região no início da década de 1920 pode-se destacar dois decisivos fatores. Em primeiro lugar, a Cooperativa Pastoral Sul Mineira, formada por recomendação do governo do Estado em 1914 para organizar as remessas de gado por Três Corações, isto é, no auge da modernização do setor, encerraria suas atividades no ano seguinte. Assim como a Companhia Pastoril Mineira, que já havia falido em 1900, as empresas locais não conseguiam se firmar no novo modelo de comercialização de gado.

Em segundo lugar, e possivelmente como causa da fragilidade do setor no Sul de Minas na estrutura da comercialização do gado, os frigoríficos paulistas vinham alterando o centro de gravidade do comércio. De um lado, a cidade de Barretos, localizada no extremo do Estado de São Paulo, aproximava-se das regiões criadoras, tornando desnecessário o trânsito das tropas pelo Sul de Minas. De outro lado, com as ferrovias alcançando as fronteiras de criação, ou ao menos de invernada, o gado não precisava mais percorrer as longas distância até o abatedouro. Ademais, para tornar ainda mais complicada a situa-

\footnotetext{
${ }^{58}$ Vale lembrar que John Wirth aponta para exportações realizadas pela Cooperativa Pastoral Sul Mineira entre os anos de 1914 e 1915. Possivelmente tal operação deve ter ocorrido por intermédios dos frigoríficos acima listados, que fariam o processamento da carne para a exportação.
} 
ção da Feira de Três Corações, ao longo da década de 1910 e 1920, a principal região de fornecimento de gado para a feira, o Triângulo Mineiro, passaria a ser atendida pelos ramais da Companhia Mogiana de Estrada de Ferro. A cidade de Passos, por exemplo, receberia a ferrovia no ano de 1921. Não é para menos que em fins da década de 1910 o transporte de gado na ferrovia mais do que dobra com relação aos primeiros anos do século XX, em que as estações das cidades como São Sebastião do Paraíso, Pratápolis (vizinha à Passos), Araguari e Uberaba, tornavam-se os principais pontos de embarque dos animais na Cia. Mogiana. ${ }^{59}$

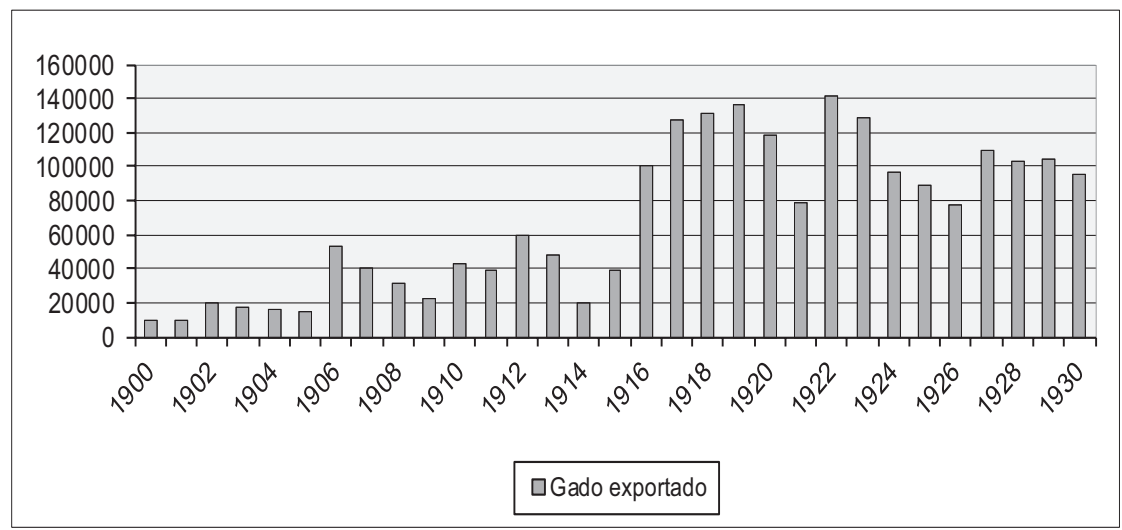

Gráfico 2 - Companhia Mogiana: cabeças de gado exportadas ao ano (1900-1930)

Fonte: Relatório da Companhia Mogiana de Estrada de Ferro, 1900-1930.

Em suma, mesmo com os pedidos de Silviano Brandão em 1890 e, mais tarde, com as tentativas das autoridades mineiras na década de 1910 para o investimento estrangeiro no processamento de carnes chegassem aos centros comerciantes de Minas Gerais, estes não se concretizariam. Os investidores preferiam se direcionar ou à Argentina ou ao interior de São Paulo, e aos estados Rio Grande

${ }^{59}$ Relatório da Companhia Mogiana de Estrada de Ferro, 1900-1930. Esse fenômeno é observado para as principais companhias de estrada de ferro paulistas (Paulista, Mogiana e Sorocabana). A partir da década de 1910 o tráfego de animais, em função da ampliação do comércio de gado bovino, amplia - ainda que pouco - sua participação na receita das companhias (em média de menos de $0,50 \%$ para os anos do século XIX, para aproximadamente 4-5\% a partir da Primeira Guerra Mundial). No que diz respeito ao tráfego anual de animais, a expansão do número de cabeças se apresenta como ainda mais representativa: de 3 a 5 mil cabeças transportadas nos anos anteriores à passagem para o século XX, e 80 mil, em média, a partir da Primeira Guerra Mundial. SAES, Flávio. As ferrovias de São Paulo, 1870-1940. São Paulo: Hucitec, 1981, p. 118-9. 
do Sul e Rio de Janeiro. Em 1928, o Estado de Minas atuaria mais energeticamente ao oferecer incentivos a investidores estrangeiros a fim de estabelecer, por meio do Decreto n. 8873, cinco matadouros frigoríficos em seus territórios. Aparece neste momento uma preocupação com a modernização do setor, inclusive com a definição das atividades do Serviço de Indústria Animal e Veterinária, da Secretaria de Agricultura de Minas Gerais. ${ }^{60}$

Por outro lado, é o momento de suspensão das Feiras de Gado do Estado de Minas Gerais, processo iniciado em 1923, com o fechamento daquelas consideradas pelo governo como "desnecessárias", incluindo anos depois as importantes feiras de Benfica, São Sebastião do Paraíso, Paraisópolis. Finalmente, em 17 de setembro de 1928, por meio do Decreto n. 8785, aquela que fora a maior feira de gado de Minas Gerais, a feira de Três Corações, teria definitivamente encerrada suas atividades. ${ }^{61}$ Era a fase de substituição do antigo sistema de comercialização do gado, da reunião de comerciantes em feiras, do papel dos negociantes e marchands no processo, para a crescente atuação dos modernos frigoríficos no setor. $O$ estado mais uma vez via a necessidade de acompanhar a modernização do setor, mas tais tentativas apresentadas pelo Decreto $n^{\circ} 8873$, morreriam neste contexto em função da crise de 1929.

\section{Considerações Finais}

Ao longo da história de Minas Gerais no período de Primeira República é possível perceber que mesmo o atraso econômico sendo identificado por alguns políticos, incorporado por projetos de modernização da economia, a região apresentou uma morosa transição para a constituição plena de seu capitalismo. Isto é, se o Estado não foi ausente em suas proposições - ao menos não no comércio de gado a falta de um mercado capitalista consolidado, por outro lado, pode ser uma explicação para o porquê de o projeto da Feira de Gado não ter avançado no período.

\footnotetext{
${ }^{60}$ Ademais, assim como em São Paulo, mediante a criação da ESALQ em 1901 (como Escola Prática Luiz de Queiroz), o estado de Minas Gerais também investiria no ensino agrícola, com a fundação das instituições: Escola Agrícola de Lavras em 1908 e Escola Superior de Agricultura e Veterinária de Viçosa em 1922. CAPDEVILLE, Guy. "O ensino superior agrícola no Brasil”. Revista brasileira de estudos de pedagogia. Vol. 72, n. 172, Brasília, 1991.

${ }^{61}$ IGLÉSIAS, 1982, p.125.
} 
É neste sentido que, na dificuldade de efetivação de setores modernos, os negócios tradicionais foram reafirmados. Assim, dentre os programas de modernização da economia pelo passado, a pecuária tornou-se um exemplo emblemático: na transição para o século XX instituiu-se a Feira de Gado de Três Corações - feira que chamamos como o mercado pontual imposto pelo Estado - que não resultou na modernização do setor na região. Diferentemente da literatura que vê fraca a participação do governo no projeto de desenvolvimento mineiro, ou mesmo a perda da oportunidade histórica, no que diz respeito à atividade de comercialização do gado, o Estado atuou desde a formação de seus mercados até nas tentativas de atrair matadouros e frigoríficos para atenuar a conhecida "perda de substância" de sua economia.

Era a tentativa de modernizar a tradicional atividade ligada ao abastecimento. Entretanto, a estrutura do negócio tornou-se limitada pela crescente concorrência da atividade em expansão e modernização nos São Paulo e Rio de Janeiro. Apesar de ser uma atividade que toma proporções representativas no período de Primeira Guerra Mundial, a pecuária mineira preservou seu velho modelo, não conseguindo absorver os aspectos modernos que eram incorporados nas produções vizinhas. Ademais, a produção de gado brasileira voltavase para o mercado interno de maneira dominante, que, como discutimos, já continha em si profundas limitações. Diferentemente das regiões de São Paulo e Rio de Janeiro, ao que parece a formação de um mercado (de consumo, de trabalho e de dinâmica econômica) foi ainda mais lenta em Minas Gerais, reduzindo de forma mais acentuada sua capacidade de acompanhar as transações comerciais ocorridas nos estados vizinhos.

Isso significa que Minas Gerais sofreu um atraso nas consolidações de suas relações capitalistas, passando a direcionar para as mãos do Estado determinadas responsabilidades no projeto de modernização da economia. Não se tratava somente do empreendimento do "ideal da modernização" enquanto um projeto, mas sim uma busca de se equiparar à economia paulista, por exemplo, que disparava à frente na concentração das atividades econômicas dentro do cenário nacional. $O$ atraso de Minas Gerais fora somente então percebido nesse sentido, na visão de que o estado perdia posições relativas no cenário econômico, não conseguia acompanhar as modernizações econômicas do período. 
Se o Estado não conquistou avanço no início do século (não só nesse ramo, mas em todos os demais), não é exclusivamente na política que temos que buscar suas causas. As autoridades teriam atuado em prol do desenvolvimento da região, estimulando a formação de mercados pontuais, mas que ainda eram restritos para estimular a expansão de atividades autônomas ao apoio do governo. Logo, devemos buscar nas condições materiais de produção, que frente àquelas de São Paulo, mostravam-se limitadas. São Paulo não somente se modernizou antes que Minas Gerais como inclusive conseguiu explorar uma forte potencialidade mineira: com a concentração dos processos mais avançados da cadeia produtiva da pecuária em São Paulo, novamente Minas Gerais se tornava subordinada, agora aos matadouros e frigoríficos de outras regiões. Mesmo com a tentativa de modernização, que caminhava para setores tradicionais da economia, esta ainda não conseguia superar as restrições deixadas pelas heranças de uma sociedade que não havia completado plenamente sua transição para uma sociedade capitalista: as causas, certamente múltiplas, para esse atraso relativo nas relações econômicas mineira, entretanto, devem ser tema para futuras pesquisas.

\section{Fontes}

"Caixa de documentos diversos (1899 a 1928)". Cartório de Registro de Títulos e Protestos de Três Corações, Cx. $n^{\circ} 1$, contendo: registros de empresas, casas comerciais, pousadas e certidões de registros para firmas comerciais atuantes no município.

BRASIL. Relatórios do Ministério da Agricultura (1884 - 1906).BRETAS. Discurso proferido a 26 de julho de 1862. Annaes do Parlamento Brazileiro: sessão de 1862. Tomo III. Rio de Janeiro: Typographia Imperial e Constitucional de J. Villeneuve \& C., 1862, p. 243.

MINAS GERAIS. Relatórios de Presidente de Província e de Estado (1887-1923).

SÃO PAULO. Relatórios de Presidente de Província e Estado, 1907. 


\section{Referências}

ABREU, J. Capistrano de. Capítulos de História Colonial: 1500-1800. Brasília: Conselho Editorial do Senado Federal, 1998.

BLASENHEIN, Peter Louis. A regional history of the Zona da Mata in Minas Gerais, Brazil: 1870-1906. Stanford: Tese - Stanford University, 1982.

BRENNER, Robert. "The agrarian roots of European capitalism". ASTON, T.H. \& PHILPIN, C.H. (Ed.). The Brenner debate. Cambridge: Past and Present Society, 1976.

CANO, Wilson. Raízes da concentração industrial no Brasil. São Paulo: Difel, 1977.

CAPDEVILLE, Guy. “O ensino superior agrícola no Brasil”. Revista brasileira de estudos de pedagogia. Vol. 72, n. 172, Brasília, 1991.

CARRARA, Ângelo Alves. Agricultura e pecuária na capitania de Minas Gerais (1674-1807). Tese (Doutorado em História) — IFCS/UFRJ, 1997.

CASTRO, Antonio Barros. "Modelo histórico latino-americano". 7 ensaios sobre a economia brasileira. Rio de Janeiro: Forense, 1969.

CHAVES, Cláudia Maria das Graças. Perfeitos negociantes: mercadores das minas setecentistas. São Paulo: Annablume, 1999.

COSTA, Fernando Nogueira da. Bancos em Minas Gerais (1889-1964). Campinas: Dissertação de Mestrado - IFCH/Unicamp, 1978.

DINIZ, Clélio Campolina. Estado e capital estrangeiro na industrialização mineira. Belo Horizonte: UFMG/PROED, 1981.

DOBB, Maurice. A evolução do capitalismo. São Paulo: Abril Cultural, 1982.

DULCI, Otavio. Política e recuperação econômica em Minas Gerais. Belo Horizonte: Ed. UFMG, 1999.

FONSECA, João Garcia da. Três Corações e sua história. Belo Horizonte: Imprensa Oficial de Minas Gerais, 1984.

FRAGOSO, João. Homens de grossa aventura. Rio de Janeiro: Civilização brasileira, 1998.

FURTADO, Celso. Formação Econômica do Brasil. Companhia Editora Nacional, 1959.

GIOVANINI, Rafael. Regiões em movimento: um olhar sobre a Geografia Histórica do Sul de Minas e da Zona da Mata (1808-1897). Belo Horizonte: Dissertação de Mestrado - UFMG, 2006.

GODOY, Marcelo Magalhães. "Minas Gerais na república: atraso econômico, estado e planejamento". Cadernos da Escola do Legislativo. Belo Horizonte, vol. 11, n. 16, 2009.

GRAÇA FILHO, Afonso de Alencastro. A Princesa do Oeste e o Mito da Decadência de Minas Gerais. São João del Rei (1831-1888). São Paulo: Annablume, 2002.

GRILO, Antônio Theodoro. Câmara Municipal de Passos - 150 anos. Passos: Câmara Municipal de Passos, 1998.

IGLÉSIAS, Francisco. "Política Econômica do Estado de Minas Gerais (1889-1930)". MONTEIRO, Norma (org). Seminário de estudos mineiros: a República Velha em Minas, 5. Belo Horizonte: UFMG, 1982.

LANNA, Ana Lúcia Duarte. A transformação do trabalho. Campinas: Editora Unicamp, 1989.

LENHARO, Alcir. As tropas da moderação. São Paulo: Símbolo, 1979.

LENIN, Vladmir Ilitch. O desenvolvimento do capitalismo na Rússia. São Paulo: Abril Cultural, 1982.

LIMA, João Heraldo. Café e indústria em Minas Gerais, 1870-1920. Petrópolis: Vozes, 1981.

MARCONDES, Renato Leite. "Formação da rede regional de abastecimento do Rio de Janeiro: a presença de negociantes de gado (1801-1811)". Topoi. Rio de Janeiro: 2001. 
MARTINS FILHO, Amilcar Vianna. O segredo de Minas: a origem do estilo mineiro de fazer política (1889-1930). Belo Horizonte: Crisálida, 2009.

MARTINS, Roberto Borges. Minas Gerais, século XIX: tráfico e apego à escravidão numa economia não-exportadora. Estudos Econômicos, Instituto de Pesquisas Econômicas - USP, v. 13, n. 1, 1983.

MAXWELL, Kenneth. A devassa da devassa. Rio de Janeiro: Paz e Terra, 1979.

MELLO, João Manuel Cardoso de. O capitalismo tardio. São Paulo: Brasiliense, 1986.

NASCIMENTO, Eduardo Rodrigues do. O comércio de gado no sudeste de Minas Gerais: Passos 18301900. Ribeirão Preto: Monografia - FEA-RP/USP, 2008.

NORONHA, Washington Álvaro de. História da cidade do Senhor Bom Jesus dos Passos. Edição Oficial Municipal, 1969.

PAIVA, Clotilde Andrade. População e economia nas Minas Gerais do século XIX. Tese (Doutorado em História Social) — FFLCH/USP, 1996.

PERINELLI NETO, Humberto. Nos quintais do Brasil: homens, pecuária, complexo cafeeiro e modernidade - Barretos (1854/1931). Franca: Tese de Doutorado - UNESP/Franca, 2009.

PETRONE, Maria Thereza Schorer. "As áreas de criação de gado". HOLANDA, Sérgio Buarque (org.). História da civilização brasileira. A época colonial. Tomo I, $2^{\circ}$ volume. Rio de Janeiro: Bertrant Brasil, 1993.

PIRES, Anderson. Café, finanças e bancos: uma análise do sistema financeiro da zona da Mata de Minas Gerais (1889-1930). São Paulo: FFLCH-USP, Tese de Doutorado, 2004.

PRADO JR., Caio. História econômica do Brasil. São Paulo: Brasiliense, 1977.

RESTITUTTI, Cristiano Corte. As fronteiras da província: rotas de comércio interprovincial (Minas Gerais, 1839-1884). Araraquara: dissertação de mestrado - Unesp, 2006.

SAES, Flávio. As ferrovias de São Paulo, 1870-1940. São Paulo: Hucitec, 1981.

SAINT-HILAIRE, Auguste de. Viagem pelas Províncias do Rio de Janeiro e Minas Gerais. Belo Horizonte/São Paulo: Itatiaia/Edusp, 1975.

SAINT-HILAIRE, Auguste de. Viagens às nascentes do rio São Francisco. Belo Horizonte/São Paulo: Itatiaia/Edusp, 1975.

SILVA, Sérgio. Expansão cafeeira e origens da industrialização no Brasil. São Paulo: Alfa-Omega, 1976.

SOUSA, Benefredo de. Boiada vai, máquina vem... Pouso Alegre: Tipografia Escola Profissional, 1975.

SUZIGAN, Wilson. Indústria brasileira. São Paulo: Hucitec, 2000.

VEIGA, Bernardo Saturnino da. Almanach Sul-Mineiro para 1874. Campanha: Typ. do Monitor Sul-Mineiro, 1874.

VISCARDI, Cláudia. M. R. "Minas Gerais no Convênio de Taubaté: Uma Abordagem Diferenciada". III Congresso Brasileiro de História Econômica e IV Conferência Internacional de História de Empresas, Anais da ABPHE. Curitiba: UFPR, 1999.

WIRTH, John. O fiel da balança: Minas Gerais na federação brasileira (1889-1937). Rio de Janeiro: Paz e Terra, 1982.

WOOD, Ellen. A origem do capitalismo. Rio de Janeiro: Zahar, 2001. 